\title{
RELAÇÃO DA PASSAGEM DE FRENTES FRIAS NA REGIÃO SUL DE MINAS GERAIS (RSMG) COM A PRECIPITAÇÃO E EVENTOS DE GEADA
}

\author{
SILVA, Luciano José da \\ Engenheiro Ambiental. Mestrando em Engenharia de Energia. Universidade Federal de \\ Itajubá - UNIFEI. IRN. Av. BPS, 1303. Pinheirinho. 37500-903. Itajubá-MG.
}

\section{REBOITA, Michelle Simões}

Docente. Dra. Meteorologia. Universidade Federal de Itajubá - UNIFEI. IRN. Av. BPS, 1303. Pinheirinho. 37500-903. Itajubá-MG.

ROCHA, Rosmeri Porfírio da

Docente. Dra. Meteorologia. Universidade de São Paulo - USP. Rua do Matão, 1226. Cidade Universitária. 05508-903. São Paulo-SP.

\begin{abstract}
RESUMO: Este estudo quantificou a passagem de frentes frias pela Região Sul de Minas Gerais (RSMG) no período de 2004 a 2010. Para tanto, utilizaram-se as variáveis atmosféricas temperatura do ar a $2 \mathrm{~m}$ de altura, pressão ao nível médio do mar e a componente meridional do vento a 10 metros de altura da reanálise ERA-Interim do European Centre for Medium-Range Weather Forecasts (ECMWF) e um esquema objetivo para identificação das frentes. Além disso, verificou-se a influência das passagens frontais frias na precipitação sazonal e ocorrência de geadas. Em média anual, há a passagem de 27 frentes pela RSMG, sendo a primavera e o inverno as estações com maior ocorrência de frentes frias. Embora a primavera seja uma estação do ano com grande frequência de passagens frontais, é no inverno que as frentes frias contribuem em maior porcentagem na precipitação. Com relação aos eventos de geada, as passagens frontais possuem pouca influência. Em todas as estações do ano, o padrão sinótico médio da evolução espaço-temporal das frentes frias é associado a um anticiclone migratório que se desloca do Pacífico em direção ao Atlântico.
\end{abstract}

Palavras-chave: Frentes Frias, Médias Sazonais, Análise Sinótica.

RELATION OF COLD FRONTS PASSAGE IN THE SOUTHERN REGION OF MINAS GERAIS STATE (SRMG) WITH PRECIPITATION AND FROST EVENTS

ABSTRACT: This study quantified the cold fronts passage over the southern region of Minas Gerais state (SRMG) from 2004 to 2010. For this, we used the atmospheric variables: air temperature at 2 meters, sea level pressure and meridional wind component at 10 meters from ERA-Interim reanalysis from European Centre for MediumRange Weather Forecasts (ECMWF) and an objective scheme to fronts identification. Moreover, we verified the influence of cold fronts passage in the seasonal precipitation and frosts. The results show that, 27 cold fronts reach SRMG for year. Spring and winter are the seasons with higher cold fronts occurrence. Although, the spring is a season with large passage of fronts, it is in the winter that the cold fronts contribute to higher percentage of precipitation. Regarding to the frosts, the cold fronts passage have little influence. In all seasons, the synoptic mean pattern of the spatial-temporal evolution of cold fronts is associated to a migratory anticyclone that displaces from Pacific to Atlantic Ocean.

Key words: Cold Fronts, Seasonal Averages, Synoptic Analysis.

\section{INTRODUÇÃO}

Os sistemas frontais, também denominados simplesmente de frentes, correspondem à região de contato entre duas massas de ar com características 
termodinâmicas distintas: em geral, uma fria e seca e outra quente e úmida. Tem-se uma frente fria quando uma massa de ar frio chega a uma determinada região em que predomina uma massa de ar relativamente mais quente. Como as frentes frias modificam as condições de tempo local, o conhecimento da climatologia desses sistemas é uma informação de grande utilidade para os previsores de tempo. Com esse intuito, Barri et al. (2011) determinaram globalmente as regiões de maior frequência de frentes frias, quentes e estacionárias, através da utilização de um esquema automático de identificação das frentes na reanálise ERA-40 do European Centre for Medium-Range Weather Forecasts (ECMWF). Nesse estudo, foi mostrado que todos os tipos de frentes são mais frequentes na região dos storm tracks $\left(40^{\circ}-60^{\circ}\right.$ de latitude em ambos os hemisférios) e que há grande ocorrência de frentes nas latitudes a cerca de $30^{\circ}$ S na costa leste da América do Sul. Resultado similar foi obtido por Simmonds et al. (2012), que utilizaram a reanálise ERA-Interim do ECMWF e outro esquema numérico de identificação de frentes.

Estudos mais regionais (SATYAMURTY e MATTOS, 1989; ReBOITA et al., 2009; CAVALCANTI e KouSKY, 2009) mostram que na América do Sul a máxima ocorrência de frentes frias é registrada no sudeste da Argentina, seguida pela região formada pelo Uruguai e sul do Brasil. Embora estes sistemas tornem-se menos frequentes à medida que as latitudes diminuem, ainda se verifica a atividade frontal no nordeste do Brasil (KOUSKY, 1979; SATYAMURTY e MATTOS, 1989; Reboita et al. 2009) e no sul da Amazônia ( $\mathrm{FISCH}$, et al. 1998). São poucos os estudos que determinaram uma climatologia de frentes frias em regiões específicas do Brasil. Uma breve revisão destes trabalhos é fornecida na sequência.

Kousky (1979) determinou a ocorrência de frentes frias em Caravelas, no sul da Bahia, no período de 1961 a 1970. Para essa região, o autor encontrou uma média anual de 15 frentes frias, sendo o inverno e a primavera as estações de maior ocorrência desses sistemas $(4,5)$ seguidas do outono $(4,4)$ e verão $(1,8)$. Lemos e Calbete (1996) ao calcularem uma climatologia de frentes frias em três bandas latitudinais (350-250 S, 250-200 S e ao norte de $20^{\circ} \mathrm{S}$ ) no período de 1987 a 1995 mostraram que a passagem frontal decresce com a diminuição da latitude. Mais tarde, RODRIGUES et al. (2004) elaboraram uma climatologia de frentes frias para o litoral de Santa Catarina ( $30^{\circ} \mathrm{S}$ e 47,50 W) com dados da reanálise do National Centers for Environmental Prediction - The National Center for Atmospheric Research (NCEP-NCAR) no período de 1990 a 1999. Os autores obtiveram uma média anual de 43 frentes frias e pouca variabilidade intersazonal (12 sistemas na primavera e variação de 9 a 10,5 sistemas nas demais estações do ano). Na cidade de São Paulo, Dametto e Rocha (2005) e Morais et al. (2010) também obtiveram a maior ocorrência de frentes frias na primavera. Segundo Dametto e Rocha (2005), nessa região a média anual é de 35 frentes e a sazonal de 10,7 sistemas na primavera, 10,2 no inverno, 8,4 no verão e 8,0 no outono.

Com base no exposto, nota-se a falta de trabalhos que investiguem localmente o comportamento climatológico das frentes frias em vários estados brasileiros, inclusive no estado de Minas Gerais. Portanto, o objetivo desse estudo é determinar a frequência da passagem desses sistemas na Região Sul de Minas Gerais (RSMG) entre 2004 a 2010. Além disso, tem-se como finalidade 
quantificar a contribuição das frentes frias para o total sazonal de precipitação e para a ocorrência de geadas.

A RSMG será representada por dados medidos na estação meteorológica da Empresa de Pesquisa Agropecuária de Minas Gerais (EPAMIG) localizada na cidade de Maria da Fé e por dados da reanálise ERA-Interim do ECMWF (DEE et al., 2011) do ponto de grade mais próximo de tal cidade. Destaca-se que esse estudo não pode ser considerado climatológico padrão porque não utiliza 30 anos de dados como recomendado pela Organização Meteorológica Mundial (OMM, 2011). Entretanto, a fim de facilitar a exposição dos resultados, muitas vezes será utilizada a denominação climatologia.

\section{Região de Estudo, Dados e Metodologia}

\section{Região de Estudo}

A RSMG (figura 1) é uma das doze mesorregiões do estado de Minas Gerais (IBGE, 2000). A sua economia é altamente agrícola, com destaque para as plantações de café. Uma das cidades da RSMG é Maria da Fé (figura 1), situada a $1250 \mathrm{~m}$ de altitude. No inverno a sua temperatura mínima pode atingir menos do que $0^{\circ} \mathrm{C}$. Já a temperatura do ar média anual dessa cidade é de $18,1^{\circ} \mathrm{C}$ e $\mathrm{o}$ total anual de precipitação é de $1763 \mathrm{~mm}$. Vale destacar que o verão é a estação do ano mais quente e chuvosa e o inverno a mais fria e seca (figura 2) e esse padrão climatológico também é característico das outras cidades da RSMG.

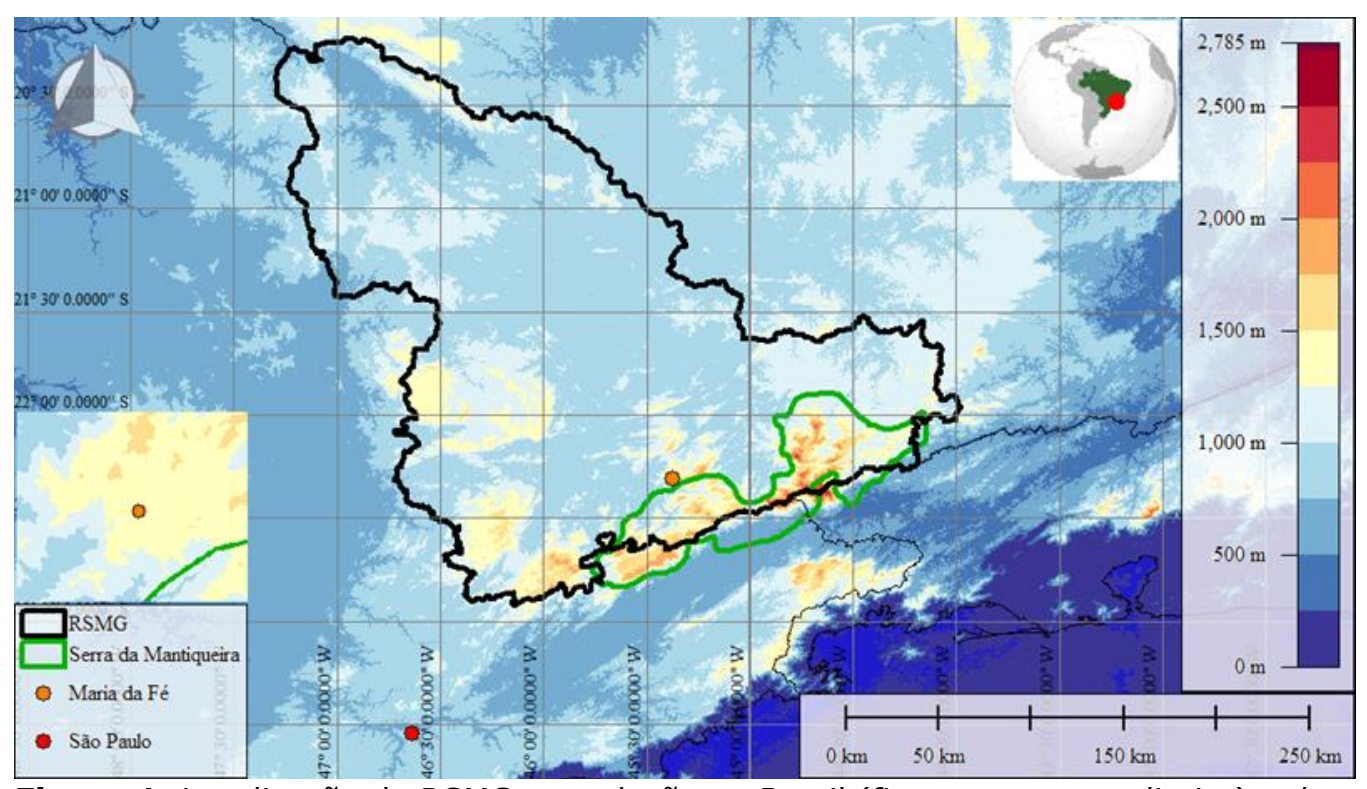

Figura 1. Localização da RSMG em relação ao Brasil (figura no topo a direita) e destaque para o relevo da região. A localização da cidade de Maria da Fé está indicada por um círculo preenchido de laranja e a da Serra da Mantiqueira por uma linha verde. 
a)

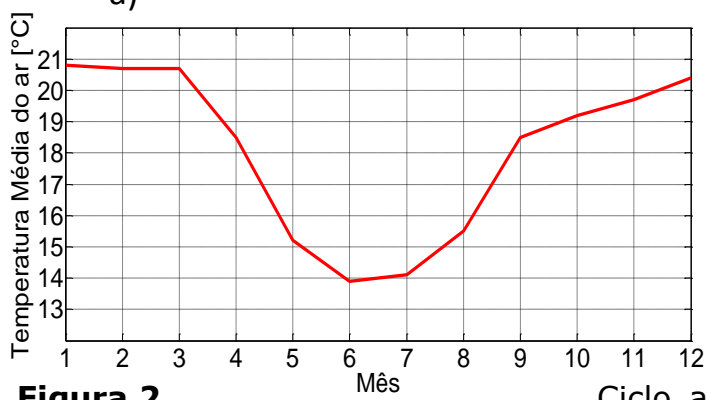

b)

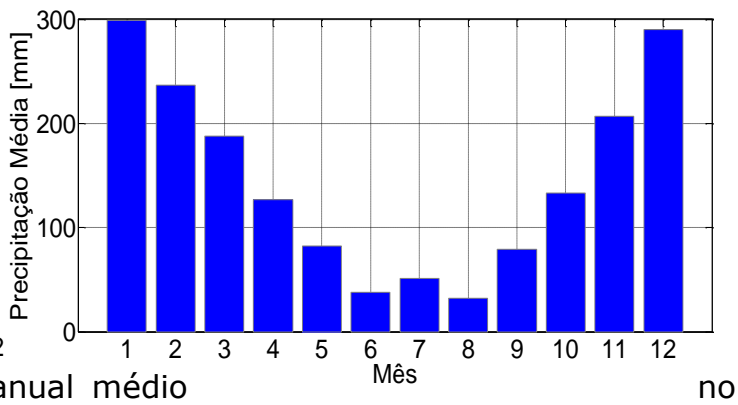
período de 2004 a 2010 da a) temperatura do ar e b) da precipitação em Maria da Fé, determinado a partir de dados medidos pela EPAMIG.

\section{Dados}

As análises para a RSMG serão baseadas nos dados de pressão ao nível médio do mar (PNMM), temperatura do ar a 2 metros de altura e vento a 10 metros de altura no período de 2004 a 2010 da reanálise ERA-Interim do ECMWF (DEE et al., 2011). Além disso, serão utilizados os totais diários de precipitação e observações de casos de geada realizadas pela EPAMIG. O período entre 2004 a 2010 foi escolhido porque corresponde ao da série histórica da EPAMIG. Como não havia registros de vento no banco de dados da EPAMIG optou-se por utilizar essa e as demais variáveis da ERA-Interim.

Atualmente existem várias reanálises disponíveis como, por exemplo, a R1 e R2 do NCEP, a ERA-15, ERA-40 e ERA-Interim do ECMWF. Dentre essas, optou-se por utilizar a ERA-Interim por: (a) ser uma reanálise estado-da-arte; (b) possuir maior resolução horizontal dentre as reanálises citadas e (c) apresentar dados de superfície muito similares às observações como mostrado por Decker et al. (2012). A reanálise ERA-Interim tem resolução espacial de $1,5^{\circ} \times 1,5^{\circ}$ de latitude por longitude e resolução temporal de 3 horas para as variáveis de superfície.

\section{Método de Identificação das Frentes Frias na RSMG}

Para identificação das frentes frias inicialmente extraiu-se da reanálise ERAInterim os dados a cada 3 horas de PNMM, temperatura do ar a $2 \mathrm{~m}$ de altura e componente meridional do vento a $10 \mathrm{~m}$ de altura, correspondentes ao ponto de grade mais próximo de Maria da Fé $\left(22,3^{\circ} \mathrm{S}\right.$ e $\left.45,4^{\circ} \mathrm{W}\right)$. A partir dos dados a cada 3 horas, calculou-se a média diária. O uso de dados médios diários justifica-se pelo fato de se eliminar (ou diminuir) sinais de circulações de escalas menores do que a sinótica reduzindo, assim, o efeito de circulações locais sob influência da topografia da região (RODRIGUES et al., 2004).

Considerou-se a passagem de uma frente fria pela RSMG quando os seguintes critérios foram estabelecidos e nesta sequência:

a) giro do vento de quadrante norte no dia anterior $(-24 \mathrm{~h})$ para quadrante sul no dia da passagem da frente fria $(0)$, o que representa uma inversão no sinal do vento meridional de negativo para positivo;

b) queda de temperatura no dia da passagem da frente fria (0) ou um dia após $(+24 \mathrm{~h})$ em relação ao dia anterior da passagem desse sistema $(-24 \mathrm{~h})$ e 
c) aumento da PNMM no dia da passagem da frente fria (0) em relação ao dia anterior $(-24 \mathrm{~h})$ e aumento no dia posterior a passagem desse sistema $(+24 \mathrm{~h})$ em relação ao dia da passagem da frente fria (0).

A figura 3 apresenta um exemplo de aplicação da metodologia de identificação de uma frente fria no dia 11 de novembro de 2010. Neste exemplo, do dia 10 para o dia 11 ocorre mudança do vento de quadrante norte para quadrante sul, queda da temperatura do ar e aumento da PNMM simultaneamente ao giro do vento. Além disso, no dia 12 a pressão atmosférica é maior do que a do dia 11 . Portanto, essas características indicam a chegada da frente fria no dia $11 / 11 / 2010$, que é confirmada através do campo da advecção horizontal de temperatura do ar e de vetores do gradiente horizontal de temperatura (figura 3 b), uma vez que a RSMG situa-se na fronteira entre a advecção quente e a fria.

a)

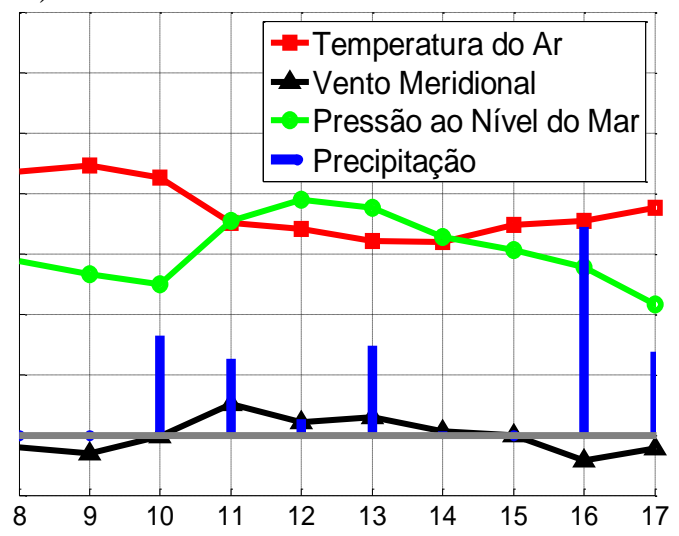

b)

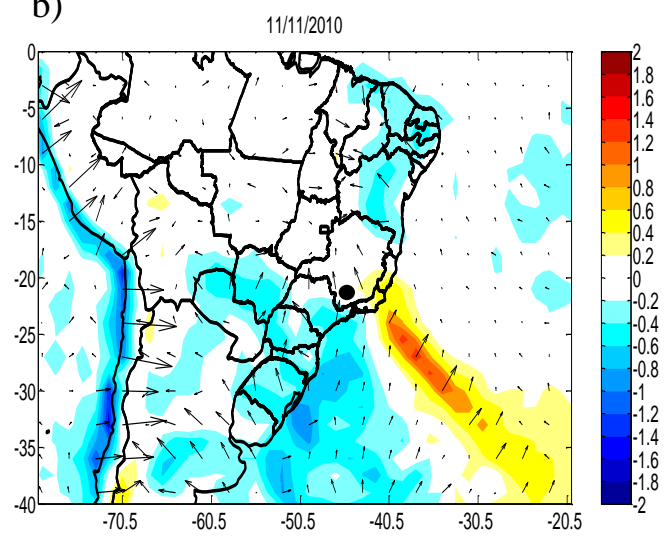

Figura 3. Passagem de uma frente fria no dia 11/11/2010: (a) evolução diária das variáveis atmosféricas entre os dias 08 e 17 de novembro de 2010 (na figura só é apresentada a evolução temporal das variáveis, os valores destas foram suprimidos) e (b) campo da advecção horizontal de temperatura do ar $\left(10^{-4}{ }^{\circ} \mathrm{C} \mathrm{s} \mathrm{s}^{-1}\right)$ e vetores do gradiente horizontal de temperatura. Em (a) a linha horizontal cinza é o limite entre os valores positivos e negativos do vento meridional. Em (b) os valores positivos indicam advecção quente (que se estende no sentido noroeste-sudeste do leste da região sudeste do Brasil até cerca de $40^{\circ} \mathrm{S}$ no oceano Atlântico) e os valores negativos advecção fria (que ocorre sobre o sul do Brasil e oceano Atlântico). A localização aproximada de Maria da Fé está indicada com um círculo preenchido.

Para validação do algoritmo, selecionou-se o ano de 2010 e elaboraram-se gráficos da evolução diária das variáveis atmosféricas (como o da figura 3a) e mapas do gradiente horizontal da temperatura do ar, advecção horizontal de temperatura e PNMM com os dados da ERA-Interim. Primeiramente, foi realizada uma busca visual das frentes frias nos gráficos e mapas. Após comparou-se os resultados obtidos visualmente com os do método objetivo. Foram identificadas 26 frentes frias visualmente e 24 objetivamente, o que corresponde a uma diferença de apenas $8 \%$. Esta diferença indica que o algoritmo possui um bom desempenho na identificação das frentes frias, já que o erro é menor do que o esperado (cerca de 20\%) quando se utiliza métodos objetivos para identificação de sistemas atmosféricos (REBOITA et al., 2010a). A título de informação adicional, para as duas frentes frias não identificadas pelo 
algoritmo não foi observado aumento da pressão atmosférica em Maria da Fé no dia posterior a passagem da frente fria (critério $\mathrm{c}$ ).

Para determinação das climatologias sazonais, as estações do ano foram definidas da seguinte forma: verão: dezembro-janeiro-fevereiro (DJF); outono: março-abril-maio (MAM); inverno: junho-julho-agosto (JJA) e primavera: setembro-outubro-novembro (SON).

\section{Precipitação e Geada Associadas à Passagem de Frentes Frias}

Um dos objetivos do presente estudo é discutir a contribuição das frentes frias para o total sazonal de precipitação e eventos de geada. No caso da precipitação, considerou-se que a chuva é decorrente de uma frente fria quando ocorrer no período entre um dia antes (chuva pré-frontal) e um dia após a passagem da frente fria (chuva pós-frontal).

Frequentemente, após a passagem de uma frente fria sobre a RSMG, a massa de ar frio na sua retaguarda invade a região. Assim, essas massas de ar podem produzir tempo bom (céu claro). Durante a atuação de uma massa de ar frio, geralmente, há ausência de nuvens e ocorre aumento de perda radiativa da superfície terrestre durante à noite, levando ao rápido resfriamento da superfície com consequente condensação do vapor d'água presente no ar. Quando a temperatura da superfície é menor do que $0{ }^{\circ} \mathrm{C}$, pode ocorrer congelamento da água e/ou o vapor d'água passar diretamente para a fase de gelo. Esses processos originam o evento que é conhecido como geada. Assim, também é objetivo do presente estudo quantificar a porcentagem de geadas associada à passagem de frentes frias entre o outono e a primavera. Episódios de geada foram associados à passagem de uma frente fria se ocorreram até três dias após este sistema.

\section{Composições de Campos Atmosféricos em Superfície}

Para analisar a evolução espacial e temporal da passagem das frentes frias sobre a RSMG foram calculadas composições (médias) de alguns campos atmosféricos. Para cada estação do ano, identificaram-se as datas de passagem de frentes frias sobre a RSMG e calculou-se a média da temperatura do ar a $2 \mathrm{~m}$ de altura, PNMM, componente meridional e direção do vento a $10 \mathrm{~m}$ de altura, desde três dias antes (dia -3) até três dias (dia +3) após a passagem das frentes frias.

\section{RESULTADOS}

\section{Climatologia das Frentes Frias}

No período de 2004 a 2010, o algoritmo identificou um total de 191 passagens de frentes frias pela RSMG, o que corresponde a uma média de 27 sistemas por ano. A tabela 1 mostra o total anual de frentes frias no período estudado, sendo os anos de 2006 e de 2009 o de menor (22) e maior (37) ocorrência desses sistemas, respectivamente. Em Maria da Fé, 2009 também foi o ano mais chuvoso entre 2004 e 2010 (tabela 3), sugerindo a contribuição do grande número de passagens frontais.

\begin{tabular}{llllllllll}
\hline Ano & 2004 & 2005 & 2006 & 2007 & 2008 & 2009 & 2010 & Média & Total \\
\hline
\end{tabular}




\begin{tabular}{llllllllll}
\hline Número de Frentes & 25 & 31 & 22 & 23 & 29 & 37 & 24 & 27,3 & 191
\end{tabular}

Tabela 1. Total anual de frentes frias na RSMG entre 2004-2010.

Em termos sazonais (tabela 2 ), o número de frentes frias é maior na primavera $(8,1)$ e inverno $(7,1)$, enquanto ocorre pequena redução no outono $(6,6)$ e verão $(5,4)$. Esta distribuição sazonal é similar àquela obtida por Cavalcanti e Kousky (2009) para todo o sudeste do Brasil (8 sistemas na primavera, 7 no inverno, 6 no outono e 4 no verão).

\begin{tabular}{|c|c|c|c|c|c|c|c|c|c|c|}
\hline Estação & 2004 & 2005 & 2006 & 2007 & 2008 & 2009 & 2010 & Média & $\begin{array}{l}\text { Desvio- } \\
\text { Padrão }\end{array}$ & Total \\
\hline Verão & 6 & 7 & 3 & 3 & 8 & 7 & 4 & 5,4 & 2,1 & 38 \\
\hline Outono & 5 & 7 & 6 & 6 & 6 & 9 & 7 & 6,6 & 1,3 & 46 \\
\hline Inverno & 6 & 6 & 8 & 7 & 6 & 11 & 6 & 7,1 & 1,9 & 50 \\
\hline Primavera & 8 & 11 & 5 & 7 & 9 & 10 & 7 & 8,1 & 2,0 & 57 \\
\hline
\end{tabular}

Tabela 2. Total sazonal de frentes frias na RSMG entre 2004-2010.

\section{Precipitação e Geadas Associadas à Passagem de Frentes Frias}

A tabela 3 e a figura 4a apresentam os totais de precipitação associados à passagem de frentes frias na RSMG. No inverno ocorre maior contribuição das frentes frias para a precipitação, ou seja, $56 \%$ do total sazonal. Esta contribuição é menor nas outras estações do ano, com cerca de $32 \%$ na primavera e outono, e $27 \%$ no verão.

\begin{tabular}{|c|c|c|c|c|c|c|c|c|c|c|c|c|}
\hline \multirow{2}{*}{ ANO } & \multicolumn{3}{|c|}{ DJF } & \multicolumn{3}{|c|}{ MAM } & \multicolumn{3}{|c|}{ JJA } & \multicolumn{3}{|c|}{ SON } \\
\hline & PT & PAFF & $\%$ & PT & PAFF & $\%$ & PT & PAFF & $\%$ & PT & PAFF & $\%$ \\
\hline 2004 & 746 & 265 & 36 & 500 & 127 & 25 & 121 & 35 & 29 & 340 & 99 & 29 \\
\hline 2005 & 770 & 249 & 32 & 458 & 277 & 61 & 73 & 57 & 78 & 334 & 195 & 58 \\
\hline 2006 & 741 & 28 & 4 & 302 & 84 & 28 & 84 & 65 & 77 & 462 & 69 & 15 \\
\hline 2007 & 896 & 88 & 10 & 260 & 75 & 29 & 146 & 90 & 61 & 320 & 117 & 37 \\
\hline 2008 & 877 & 407 & 46 & 582 & 99 & 17 & 141 & 62 & 44 & 475 & 134 & 28 \\
\hline 2009 & 1086 & 327 & 30 & 297 & 91 & 31 & 207 & 98 & 47 & 554 & 195 & 35 \\
\hline 2010 & 634 & 196 & 31 & 386 & 131 & 34 & 71 & 67 & 95 & 448 & 135 & 30 \\
\hline Total & 5750 & 1561 & 27 & 2784 & 884 & 32 & 843 & 473 & 56 & 2932 & 943 & 32 \\
\hline
\end{tabular}

Tabela 3. Percentual de precipitação associado à passagem de frentes frias pela RSMG. As iniciais PT e PAFF significam, respectivamente, precipitação sazonal total $(\mathrm{mm})$ e precipitação $(\mathrm{mm})$ associada à passagem de frentes frias. A última linha da tabela indica a soma dos casos de PT e PAFF e a média no caso das porcentagens (\%). 
a)

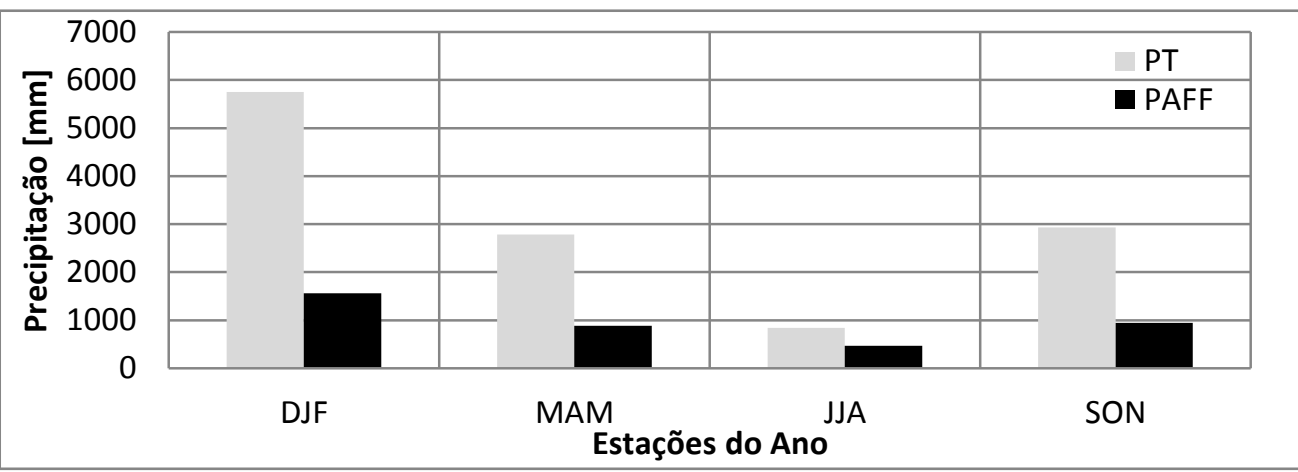

b)

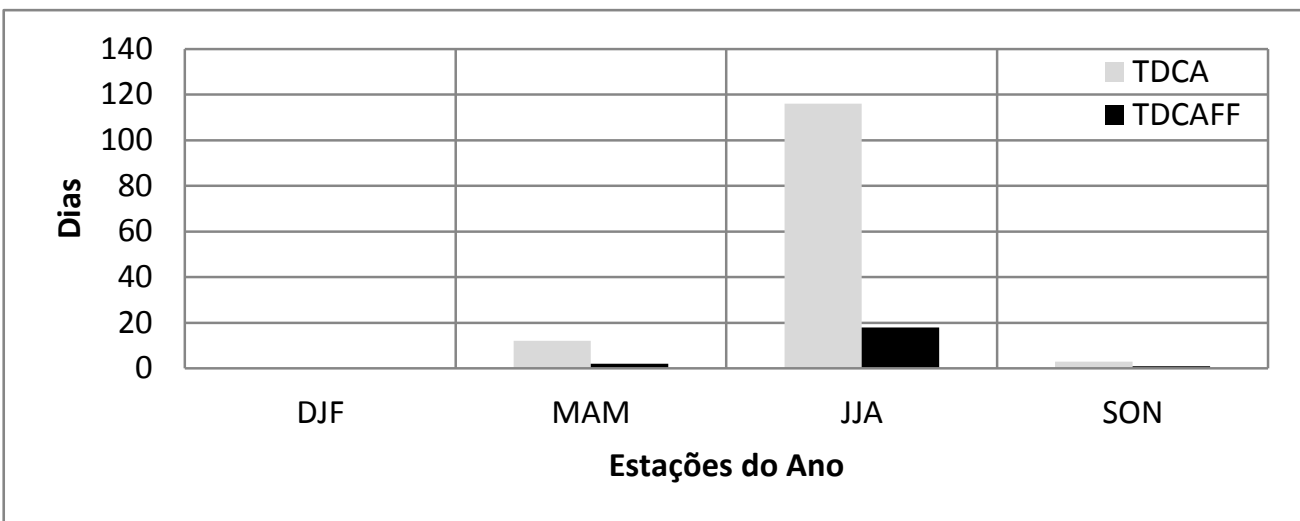

Figura 4 (a) Precipitação total (PT) e precipitação associada à passagem de frentes frias (PAFF) e (b) total de dias com ocorrência de geadas (TDCA) e total de dias com ocorrência de geadas associadas à passagem de frentes frias (TDCAFF) na RSMG no período de 2004 a 2010.

Embora a primavera seja uma estação do ano com grande frequência de frentes frias, a contribuição destes sistemas para a chuva sazonal é menor, uma vez que outros fenômenos contribuem para a precipitação, tais como: a atividade convectiva local característica dessa época do ano, a atividade convectiva organizada pela convergência de umidade proveniente do Atlântico Sul e/ou da Amazônia e a formação de cavados invertidos em superfície no campo da pressão associados à vorticidade ciclônica. Estes fenômenos também estão presentes no verão e contribuem mais para o total de precipitação do que as frentes frias.

No inverno, a convecção praticamente desaparece sobre a RSMG. Entre os diferentes fatores que contribuem para isso tem-se a atuação do setor oeste do Anticiclone Subtropical do Atlântico Sul (ASAS) sobre o sudeste do Brasil (ReboitA et al., 2010b) que desfavorece as condições propícias à chuva. Portanto, na RSMG a chuva na estação fria ocorre quando as frentes frias são intensas o suficiente para atingir a região ou quando cavados invertidos em superfície se formam entre a região sudeste do Brasil e o Atlântico Sul. Esta última informação é obtida através da análise do campo espacial da PNMM nos casos de chuva não-associados à ocorrência frontal (figura não apresentada).

Os percentuais de ocorrência de geadas associados à passagem de frentes frias na RSMG são apresentados na tabela 4 e figura 4b. Na primavera, dos sete anos 
em estudo, ocorreram apenas três casos de geada e um estava associado à passagem frontal. Essas baixas ocorrências influenciam o valor percentual (tabela 4) que acaba indicando a primavera como a estação do ano em que há maior associação entre as frentes frias e os casos de geada ( $33 \%$ dos casos). Porém, nenhuma conclusão pode ser obtida em virtude do baixo número desses eventos. Já o inverno e o outono são as estações do ano com maior número de eventos de geada, mas estes também possuem fraca associação com as frentes frias (17\% e $15 \%$ respectivamente). No verão, a ocorrência de geadas não foi analisada.

\begin{tabular}{cccccccccc}
\hline \multirow{2}{*}{ ANO } & \multicolumn{3}{c}{ MAM } & \multicolumn{3}{c}{ JJA } & \multicolumn{3}{c}{ SON } \\
\cline { 2 - 9 } & TDCA & DCAFF & \% & TDCA & DCAFF & \% & TDCA & DCAFF & \% \\
\hline 2004 & 2 & 0 & 0 & 20 & 3 & 15,0 & 1 & 0 & 0.0 \\
2005 & 0 & 0 & 0 & 8 & 0 & 0 & 0 & 0 & 0.0 \\
2006 & 3 & 0 & 0 & 19 & 6 & 31,6 & 1 & 1 & 100 \\
2007 & 3 & 2 & 66,7 & 15 & 4 & 26,7 & 0 & 0 & 0.0 \\
2008 & 2 & 0 & 0 & 17 & 0 & 0 & 1 & 0 & 0.0 \\
2009 & 0 & 0 & 0 & 9 & 2 & 22,2 & 0 & 0 & 0.0 \\
2010 & 2 & 0 & 0 & 28 & 3 & 10.7 & 0 & 0 & 0.0 \\
Total & 12 & 2 & $\mathbf{1 6 , 7}$ & 116 & 18 & $\mathbf{1 5 , 5}$ & 3 & 1 & $\mathbf{3 3 , 3}$ \\
\hline
\end{tabular}

Tabela 4. Percentual de ocorrência de geada associado à passagem de frentes frias na RSMG. As iniciais TDCA e DCAFF significam, respectivamente, total sazonal de dias com ocorrência de geada e total de dias com ocorrência de geada associada à passagem de frentes frias.

Os resultados da tabela 4 e figura $4 \mathrm{~b}$ indicam que o anticiclone migratório na retaguarda das frentes frias não é o único fator responsável pela ocorrência de geadas na RSMG. Um mecanismo importante para as geadas seria o predomínio do ASAS ou de anticiclones na costa leste do Brasil que muitas vezes se associam com o ASAS. Para verificar isso, calcularam-se composições para o campo de PNMM nos casos de geada que não estiveram associados às passagens de frente frias (isto é, que ocorreram a partir do quarto dia após a passagem frontal) apenas para o inverno. A figura $5 a$ mostra que as geadas estão associadas a um anticiclone em superfície (centrado em $40^{\circ} \mathrm{W}$ e $29^{\circ} \mathrm{S}$ ) que está praticamente conectado ao ASAS. Esse anticiclone possui características distintas do anticiclone migratório que acompanha as frentes frias. Como mostra a figura $5 b$, o anticiclone migratório no terceiro dia após a passagem frontal está centrado a cerca de $5^{\circ}$ para leste comparado ao da figura $5 a$, além disso, é cerca de $3 \mathrm{hPa}$ mais intenso (possui centro com $1024 \mathrm{hPa}$, enquanto o da figura 5 a possui $1021 \mathrm{hPa}$ ). Por fim, o predomínio de um sistema de alta pressão na RSMG mostrado na figura 5 a durante o inverno, quando também o ar está mais seco, propicia condições de céu claro, contribuindo para aumentar a perda radiativa e o grande resfriamento noturno da superfície, favorecendo a formação de geada nas primeiras horas da manhã. 
a)

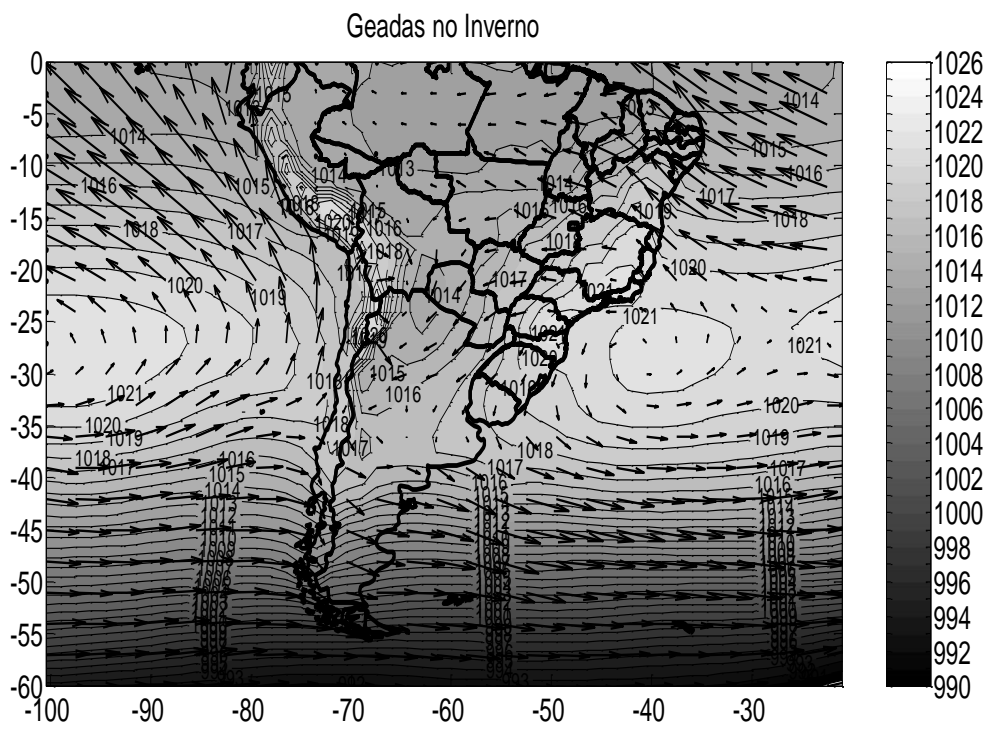

b)

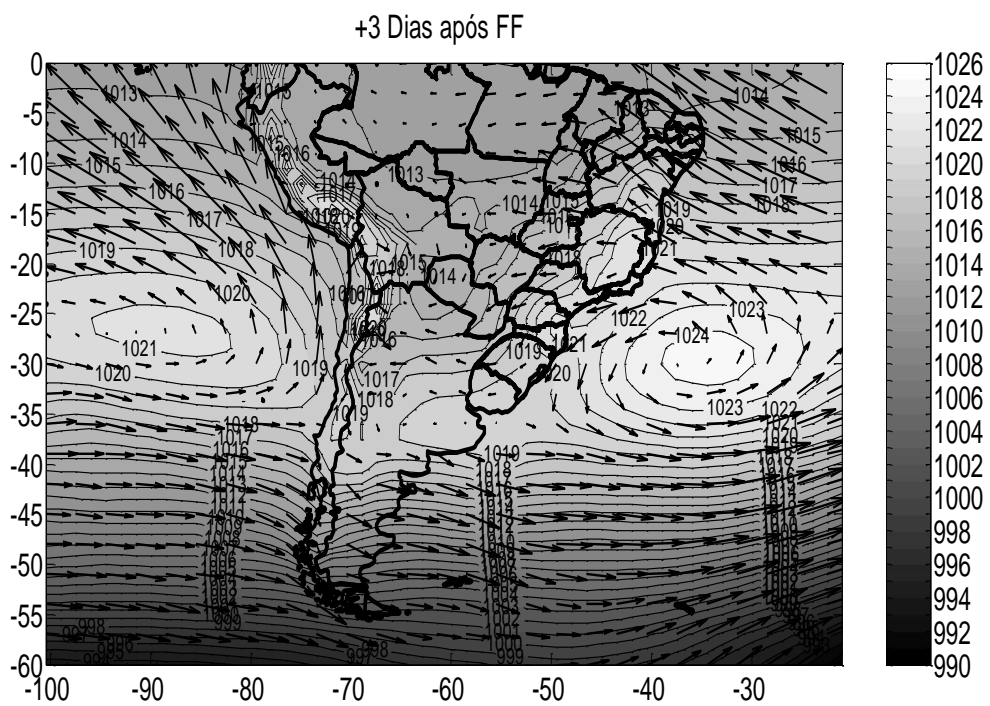

Figura 5. Média da PNMM (hPa) e do vento a $10 \mathrm{~m}$ de altura, no inverno: (a) nos dias em que ocorreram geadas a partir do quarto dia após a passagem de frentes frias pela RSMG e (b) no terceiro dia após a passagem frontal. 


\section{Composições dos Campos Atmosféricos em Superfície}

A figura 6 mostra as médias sazonais da temperatura do ar a $2 \mathrm{~m}$ de altura, da PNMM e do vento meridional a $10 \mathrm{~m}$ de altura desde 3 dias antes até 3 dias após a passagem das frentes frias em Maria da Fé (RSMG).

a)

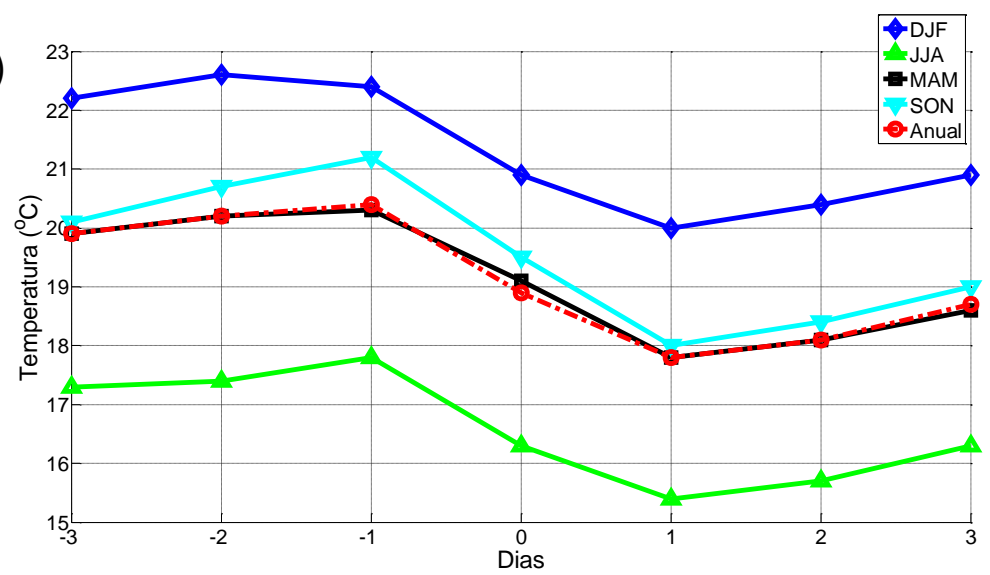

b)
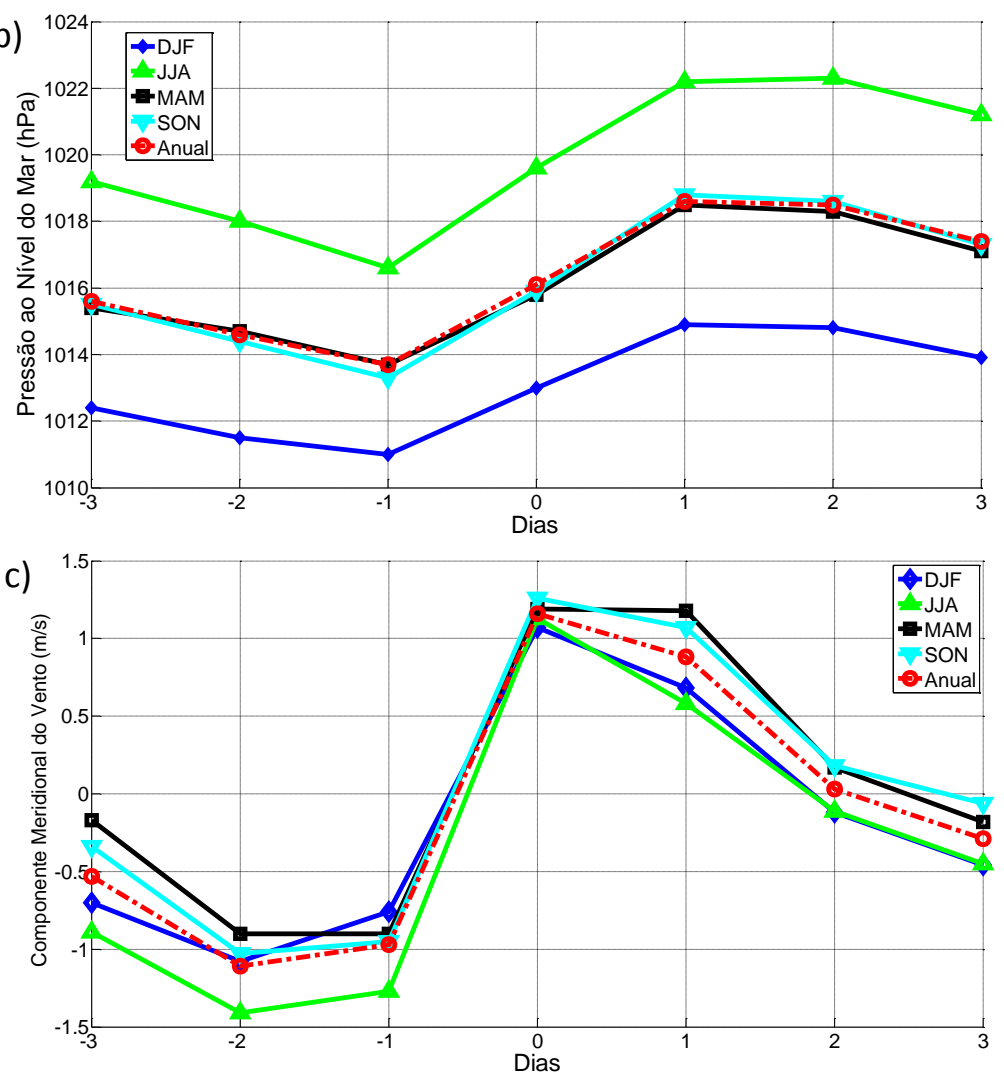

Figura 6. Média sazonal da (a) temperatura a $2 \mathrm{~m}$ de altura $\left({ }^{\circ} \mathrm{C}\right)$, (b) pressão ao nível do mar $(\mathrm{hPa})$ e (c) componente meridional do vento $\left(\mathrm{m} \mathrm{s}^{-1}\right)$ desde 3 dias antes até 3 dias após a passagem de frentes frias na RSMG. A linha com marcadores na forma de losango indica o verão, com triângulo o inverno, com quadrado o outono, com triângulo invertido a primavera e com círculo a média anual. 
Com relação à temperatura do ar (figura 6a), as quatro estações do ano mostram uma evolução temporal similar: nos três dias anteriores à passagem da frente fria $(-3,-2$ e -1$)$ ocorre aumento gradativo da temperatura do ar (exceto no verão, quando nesses três dias a temperatura é praticamente constante). A temperatura diminui no dia da passagem frontal (0) e no dia posterior $(+1)$, voltando a aumentar a partir do dia +2 . Nos dias que antecedem à passagem da frente fria, o aumento de temperatura decorre do escoamento de quadrante norte (figura $6 c$ ) que induz a advecção de ar quente na RSMG. Como no dia -1 a frente fria situa-se ao sul da RSMG, predominam ventos de quadrante norte nesta região que são opostos ao gradiente meridional de temperatura (figura não apresentada) com consequente advecção quente.

A figura $6 \mathrm{~b}$ mostra que a evolução temporal da PNMM é semelhante em todas as estações do ano. Em geral, nos três dias que antecedem a passagem da frente fria a pressão cai gradativamente até o dia anterior $(-1)$. Entre o dia anterior e o dia da passagem desse sistema (0) ocorre aumento brusco de pressão, que continua aumentando até o dia +2 . Entre os dias +2 e +3 a pressão começa a diminuir indicando o enfraquecimento do anticiclone polar na retaguarda da frente fria.

Com relação à componente meridional do vento (figura 6c), durante os três dias que antecedem a passagem da frente fria, os ventos são de quadrante norte, tornando-se de sul no dia da passagem desse sistema (0) e se mantém de sul até um dia após $(+1)$ a passagem da frente fria. No dia +2 , diminui a intensidade da componente meridional, indicativo de nova mudança do vento de sul para norte. No entanto, no outono e primavera os ventos ainda se mantêm de quadrante sul até o dia +2 , enquanto no verão e inverno são de quadrante norte. No dia +3 após a passagem frontal, os ventos se tornam de quadrante norte em todas as estações do ano. É importante notar que a intensidade do vento de quadrante sul no dia da passagem da frente fria (0) é muito semelhante $(\sim 1,2 \mathrm{~m} / \mathrm{s})$ em todas as estações do ano.

Para o verão e inverno, as figuras 7 e 8 apresentam as composições dos campos de PNMM e vento a $10 \mathrm{~m}$ de altura desde três dias antes (-3) até dois dias depois $(+2)$ da passagem de frentes frias por Maria da Fé. Em todas as estações do ano, a passagem de frentes frias na RSMG está associada a um anticiclone migratório na retaguarda desses sistemas que se desloca do Pacífico para o Atlântico entre as latitudes de $40^{\circ}-35^{\circ} \mathrm{S}$ no verão, $35^{\circ}-30^{\circ} \mathrm{S}$ no inverno e $37^{\circ}$ $33^{\circ} \mathrm{S}$ nas estações de transição.

O padrão sinótico médio da evolução temporal das frentes frias que chegam à RSMG no verão é muito similar ao encontrado por Rodrigues et al. (2004), que estudaram as frentes frias que atuam no litoral de Santa Catarina, e ao de Garreaud e Wallace (1998), que investigaram as incursões de ar frio nas regiões subtropical e tropical da América do Sul. No verão, no dia -3 (figura 7a) observa-se uma baixa termo-orográfica entre o noroeste da Argentina e o Paraguai, ventos intensos de nordeste próximo à costa das regiões sul e sudeste do Brasil e uma área de alta pressão e ventos fracos sobre o centro-leste da Argentina (em $35^{\circ} \mathrm{S}$ ). A circulação anti-horária nessa região de alta pressão torna-se mais evidente à medida que interage com um anticiclone migratório 
que se desloca do Pacífico em direção ao Atlântico (dias -2 e -1). No dia -2 (figura 7b), os ventos no setor leste da alta pressão continental convergem com os ventos de nordeste no ramo oeste do ASAS permitindo a identificação de uma frente fria desde o extremo sul do Rio Grande do Sul até o cavado localizado em $43^{\circ} \mathrm{S}$ e $47^{\circ} \mathrm{W}$ sobre o oceano Atlântico. No dia -1 (figura 7c), imersa numa área de baixa pressão, a frente fria localiza-se entre os estados do Paraná e São Paulo e, no dia 0 (figura 7d), quando o anticiclone migratório da sua retaguarda está centrado no sul do Uruguai, a frente alcança a cidade de Maria da Fé. Um dia após ter passado por essa cidade (figura 7e), a frente fria encontra-se afastada da costa brasileira e o cavado associado a ela está enfraquecido. No dia +2 (figura 7f), o anticiclone migratório é "embebido" pelo ASAS e o padrão climatológico do verão tende a se reestabelecer, predominando ventos de nordeste sobre a costa sul-sudeste do Brasil.

Ao se comparar o padrão sinótico médio associado à passagem de frentes frias em Maria da Fé nas estações do verão (figura 7) e inverno (figura 8), a primeira constatação é de que no inverno: (a) os sistemas atmosféricos (exemplo: altas semipermanentes, escoamento de oeste) estão deslocados em cerca de $5^{\circ}$ para norte, (b) que não é tão evidente a baixa termo-orográfica no norte da Argentina e (c) que há um cavado pronunciado no dia -1 sobre o oceano Atlântico entre as latitudes de $30^{\circ}$ e $45^{\circ} \mathrm{S}$. Da mesma forma que no verão, no dia -3 no inverno (figura 8 a) há uma área com ventos fracos sobre a Argentina, mas agora localizada no centro-norte desse país. Ainda no dia -3, na costa da região sul do Brasil observa-se um cavado com pequena amplitude. No dia -2 (figura 8b), o escoamento ao sul desse cavado começa a exibir uma ligeira ondulação (próximo de $38^{\circ} \mathrm{S}$ e $50^{\circ} \mathrm{W}$ ) e um anticiclone migratório proveniente do Pacífico começa a invadir a região central da Argentina. Os ventos de quadrante sul associado a este anticiclone ao interagirem com os de quadrante norte do setor leste do cavado invertido em superfície e com os ventos do ASAS, tornam evidente uma frente fria na costa sul do Brasil. À medida que o anticiclone migratório se propaga para leste, do Pacífico para o Atlântico, sofre interação com a cordilheira dos Andes e, a sotavento, apresenta um alongamento em direção ao equador (dia -1, figura $8 \mathrm{c}$ ). Detalhes sobre os padrões sinóticos de interação de sistemas de alta e baixa pressão com os Andes são descritos em Gan e Rao (1994). No dia -1 (figura 8c), o cavado a leste do continente aprofunda-se e estende-se de $45^{\circ}$ a $30^{\circ} \mathrm{S}$. Com isso, os ventos a oeste desse sistema e os do setor leste do anticiclone migratório intensificam os ventos de quadrante sul, contribuindo para o deslocamento da frente fria, orientada norte-sul, que no dia -1 atinge a divisa do Paraná com São Paulo. Isso é uma característica distinta entre o inverno e verão, já que no verão o cavado associado à frente fria possui menor amplitude no escoamento de oeste. Esta característica também foi destacada por RODRIGUES et al. (2004). No dia 0 (figura 8d), a frente fria, com orientação noroeste-sudeste, encontra-se sobre a RSMG. Nesse dia, o anticiclone migratório está centrado sobre o continente entre o norte da Argentina e a região sul do Brasil. No dia +1 (figura $8 \mathrm{e})$, esse anticiclone invade grande parte do sudeste do Brasil, e a frente fria é identificada apenas sobre o oceano Atlântico. No dia +2 (figura $8 f$ ), os campos de vento e pressão não permitem mais identificar a frente fria, e a região sudeste do Brasil está sob a ação da porção oeste do anticiclone migratório, que agora está em sua maior parte sobre o oceano Atlântico e com centro em cerca de $27^{\circ} \mathrm{S}$. 


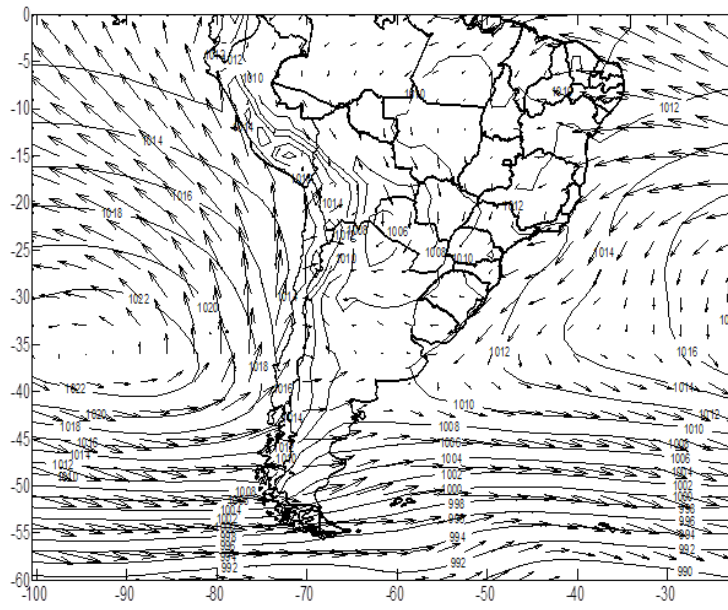

a) -3

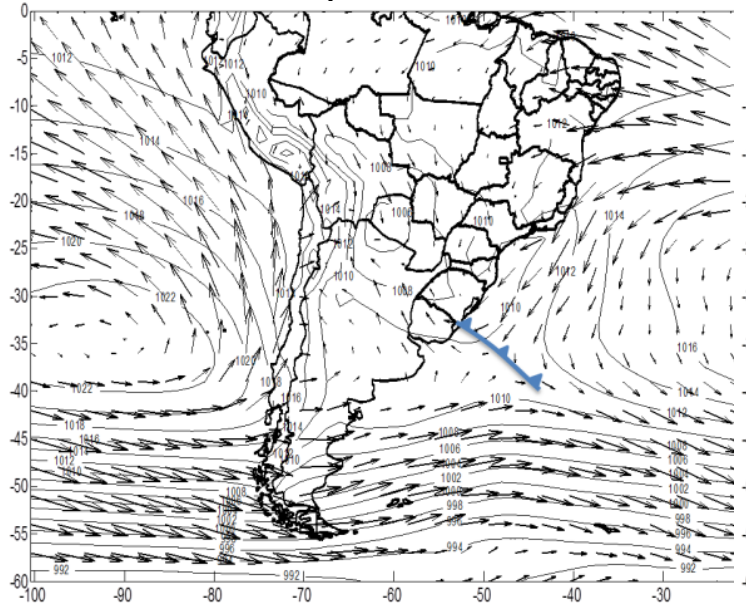

(b) -2

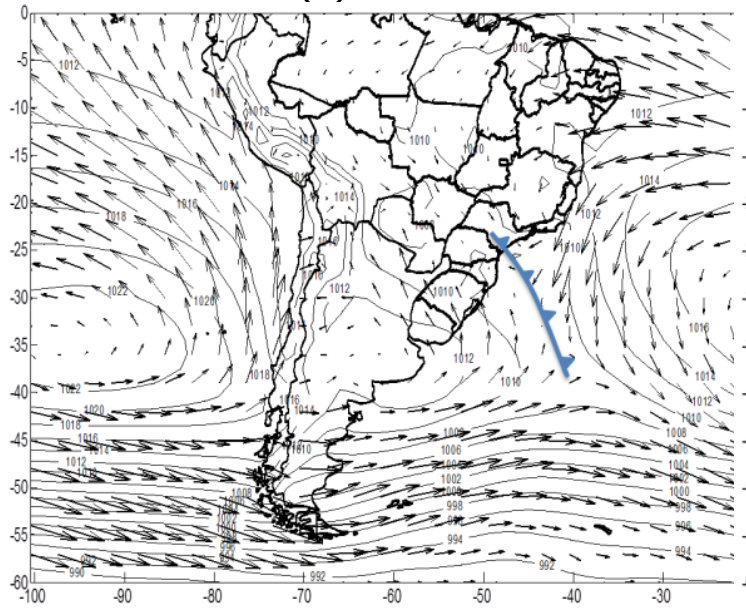

(c) -1

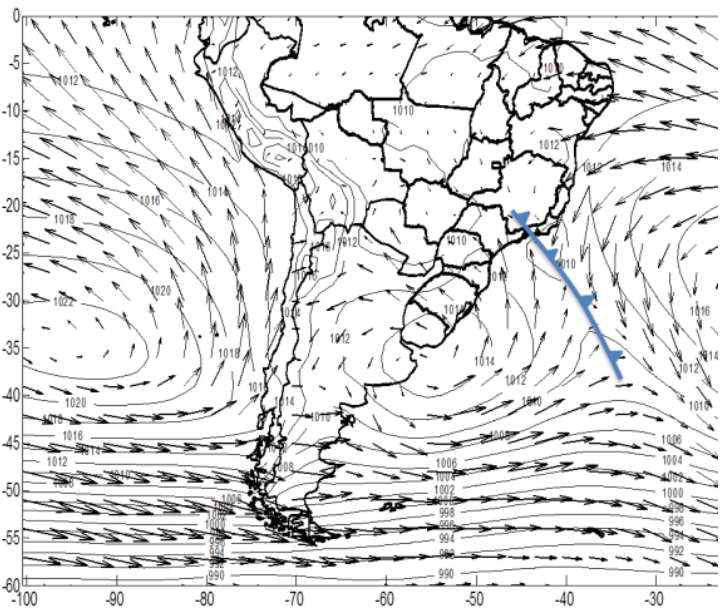

(d) 0

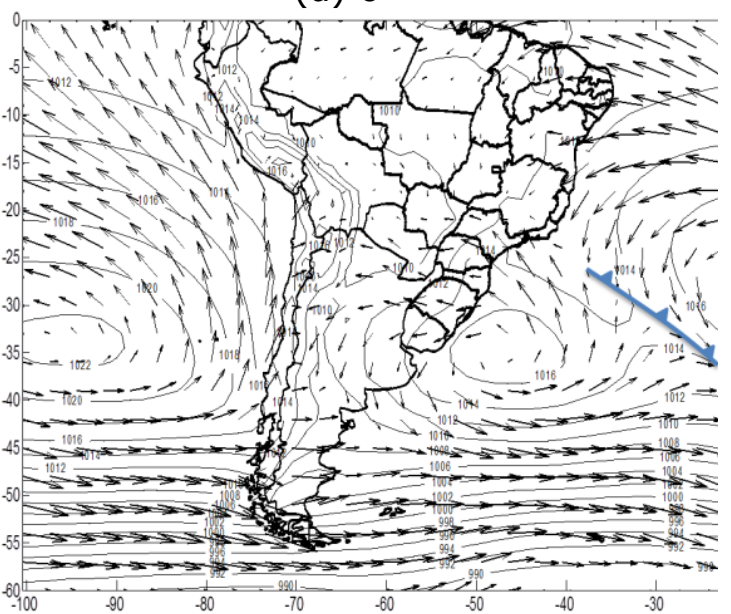

(e) +1

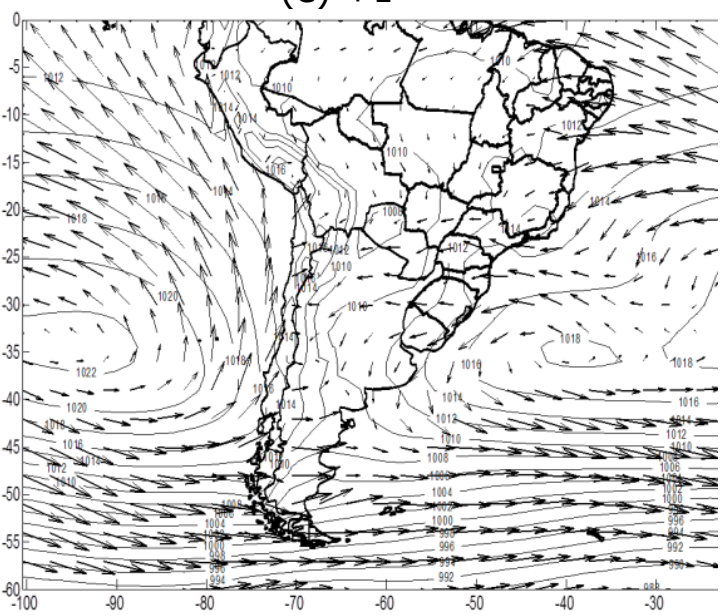

(f) +2

Figura 7. Composições dos campos de PNMM (hPa) e vento a 10 metros de altura para os dias de passagem de frentes frias no verão (2004-2010) na RSMG. Período préfrontal: (a) 3 dias antes, (b) 2 dias antes e (c) 1 dia antes; (d) passagem da frente fria (dia 0) e período pós-frontal: (e) 1 dia depois e ( $\mathrm{f}$ ) dois dias depois após a passagem do sistema. As Frentes Frias estão indicadas nas figuras com triângulos ligados a uma linha. 
Revista Brasileira de Climatologia

ISSN: 1980-055x (Impressa) 2237-8642 (Eletrônica)

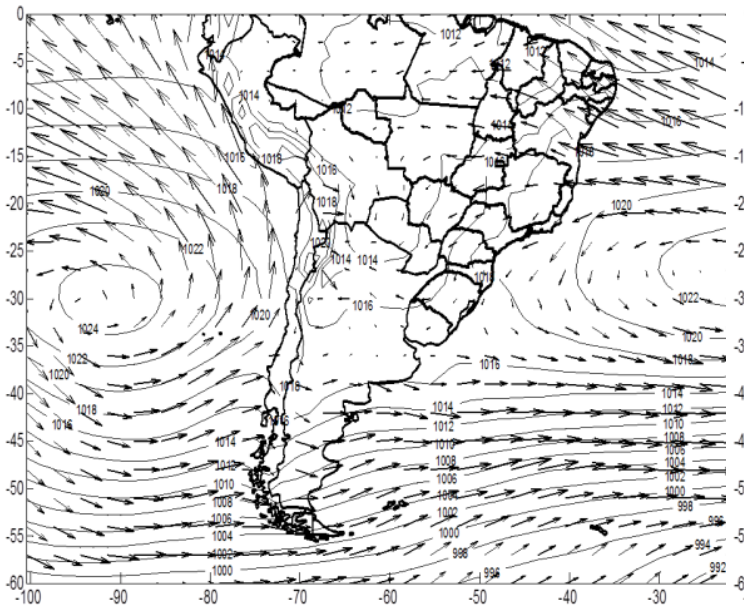

(a) -3

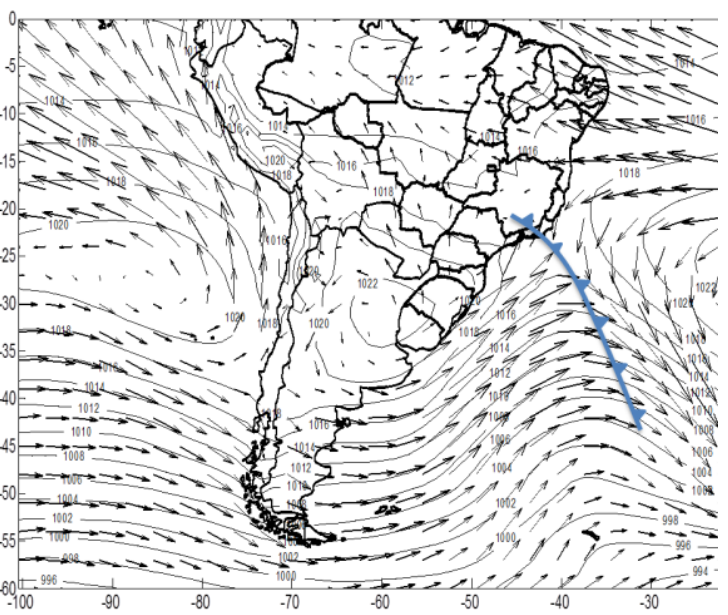

(d) 0

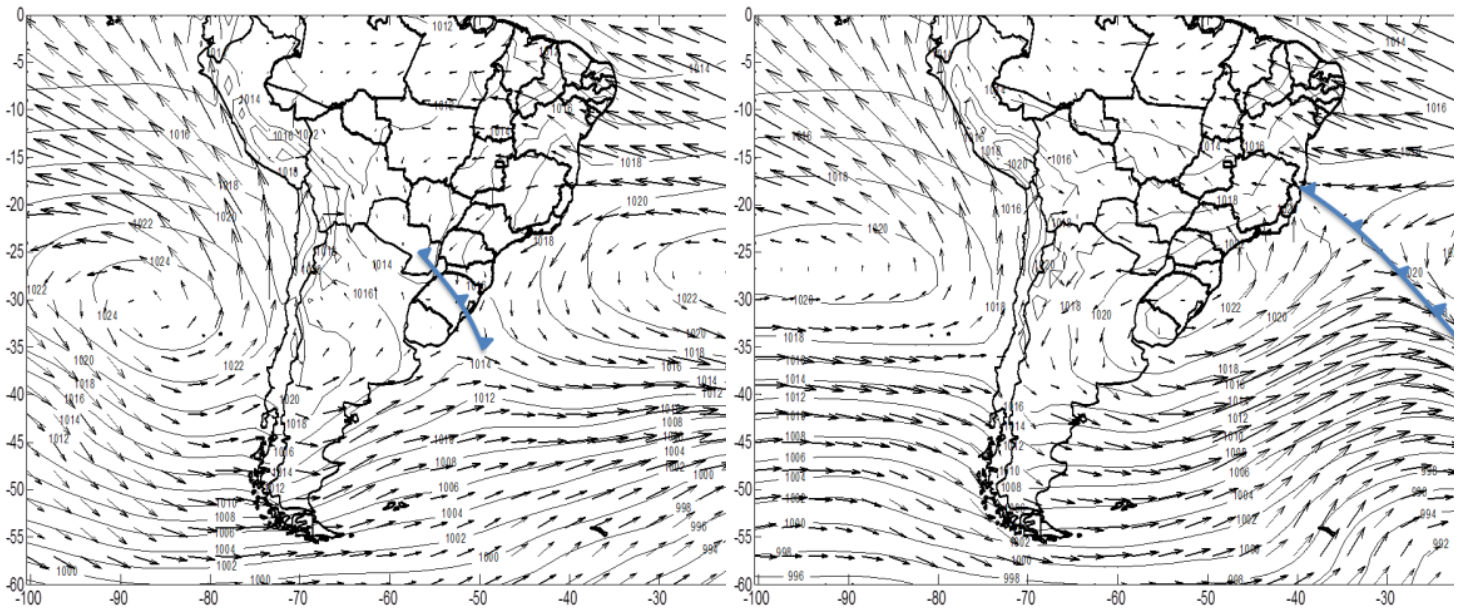

(b) -2

(e) +1

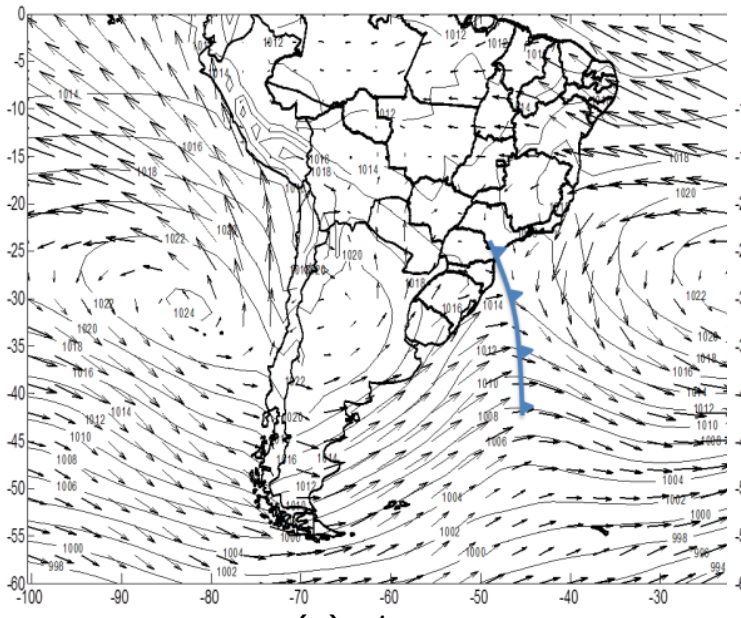

(c) -1

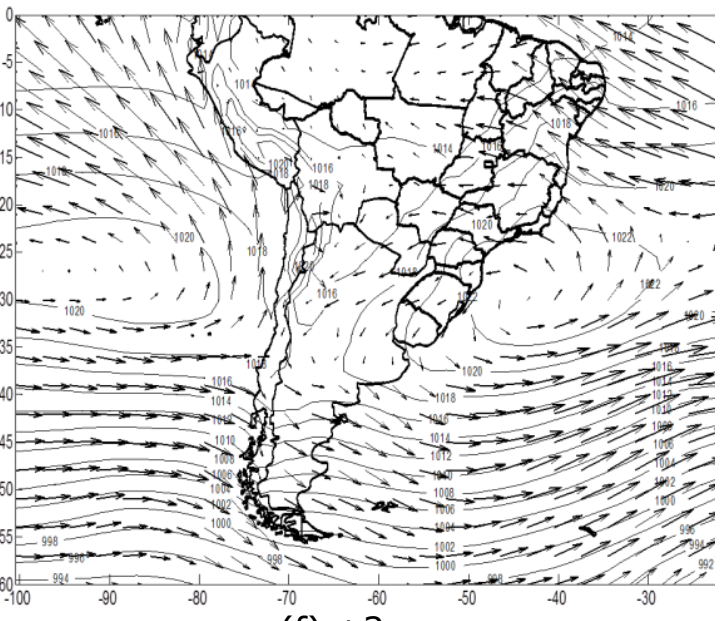

Figura 8. Similar à figura 7, mas para o inverno.

(f) +2 
A situação sinótica geral da passagem de frentes frias na RSMG é muito parecida em todas as estações do ano. Por esse motivo, só é apresentada uma breve descrição da passagem desses sistemas no outono e primavera. Nessas estações de transição (figuras não mostradas), no dia -2 há um cavado no escoamento de oeste próximo de $38^{\circ} \mathrm{S}$ e $50^{\circ} \mathrm{W}$, ligeiramente, com maior amplitude no outono. Conectada a esse cavado, desenvolve-se uma frente fria que se estende até o Uruguai. No dia -1, o cavado desloca-se para leste, o anticiclone migratório invade o centro-norte da Argentina e a frente fria localizase na divisa do Rio Grande do Sul com Santa Catarina. No dia 0, a frente fria chega à Maria da Fé e o anticiclone migratório ainda atua sobre a Argentina, Uruguai e Rio Grande do Sul. No dia +1 esses sistemas deslocam-se para o oceano Atlântico.

\section{CONCLUSÃO}

A fim de contribuir para a caracterização climática da RSMG (representada pelo município de Maria da Fé), este trabalho teve como objetivo determinar a climatologia da passagem de frentes frias e a contribuição destas para a precipitação e eventos de geada. Entre 2004 e 2010, as frentes frias foram identificadas através de critérios objetivos aplicados às variáveis atmosféricas: temperatura do ar a $2 \mathrm{~m}$ de altura, pressão ao nível médio do mar e componente meridional do vento a $10 \mathrm{~m}$ de altura da reanálise ERA-Interim do ECMWF.

No período em estudo, registraram-se a passagem de 191 frentes frias na RSMG o que corresponde a uma média anual de 27 frentes. Em termos sazonais, a maior ocorrência foi registrada na primavera $(8,1)$ e inverno $(7,1)$ seguidos do outono $(6,6)$ e verão $(5,4)$. Embora a primavera seja uma estação do ano com grande atividade frontal, é no inverno que as frentes frias contribuem com maior porcentagem para a precipitação. Esse fato está associado às características climáticas do sudeste do Brasil, pois na primavera há outros mecanismos e sistemas importantes para a precipitação. Com base nas observações de ocorrências de geada feitas pela EPAMIG, também se avaliou a contribuição das frentes frias para esses eventos. Existe fraca associação das geadas com a passagem das frentes frias, apenas cerca de $15 \%$ e $17 \%$, no inverno e outono, respectivamente. Em geral, os eventos de geada ocorrem na presença de um anticiclone na costa do Brasil que possui características (localização e intensidade) distintas dos anticiclones pós-frontais.

Os padrões sinóticos médios associados com a passagem das frentes frias na RSMG foram revelados através da análise de composição. Em todas as estações do ano, a passagem das frentes frias está associada a um anticiclone migratório que se desloca do Pacífico em direção ao Atlântico. No verão, esse anticiclone localiza-se a cerca de $5^{\circ}$ mais ao sul do que no inverno. Outra diferença entre essas duas estações do ano é que no verão a frente fria ocorre devido à convergência dos ventos do setor leste do anticiclone migratório com os ventos do lado oeste do ASAS, enquanto no inverno, os ventos do anticiclone migratório são reforçados pelo escoamento "upstream" de um cavado localizado ao seu lado leste. Um dia antes da frente fria chegar à RSMG, ela localiza-se na divisa dos estados do Paraná e São Paulo. 


\section{AGRADECIMENTOS}

Os autores agradecem à EPAMIG, por ceder os dados de temperatura do ar, precipitação e registros de geada da estação meteorológica de Maria da Fé, ao ECMWF, por disponibilizar a reanálise ERA-Interim, e ao Conselho Nacional de Desenvolvimento Científico e Tecnológico (CNPq), por financiar essa pesquisa.

\section{REFERÊNCIAS}

BARRI, G.; REEDER, M.J.; CHRISTIAN, J. A global climatology of atmospheric fronts. Geophysical Research Letters, v.38, L04809, 2011.

CAVALCANTI, I.F.A.; KOUSKY, V.E. Frentes frias sobre o Brasil. In: CAVALCANTI, IRACEMA FONSECA DE ALBURQUERQUE; FERREIRA, NELSON JESUS; SILVA, MARIA GERTRUDES ALVAREZ JUSTI DA; SILVA DIAS, MARIA ASSUNÇÃO FAUS DA SILVA DIAS (Org.). Tempo e Clima no Brasil. São Paulo: Oficina de Textos, 2009. p.135-147.

DAMETTO, G.; ROCHA, R. P. Características Climáticas dos Sistemas Frontais na Cidade de São Paulo. Relatório FAPESP, 2005.

DECKER, M., BRUNKE, M. A.; WANG, Z.; SAKAGUCHI, K.; ZENG, X.; BOSILOVICH, M. G. Evaluation of the Reanalysis Products from GSFC, NCEP, and ECMWF Using Flux Tower Observations. Journal of Climate, v.25, p.1916$1944,2012$.

DEE, D. P.; UPPALA' S. M.; SIMMONS. A. J.; BERRISFORD, P.; POLI, P.; KOBAYASHI, S.; ANDRAE, U.; BALMASEDA, M. A.; BALSAMO, G.; BAUER, P.; BECHTOLD, P.; BELJAARS, A. C. M.; VAN DE BERG, L.; BIDLOT, J.; BORMANN, N.; DELSOL, C.; DRAGANI, R.; FUENTES, M.; GEER, A. J.; HAIMBERGER, L.; HEALY, S. B.; HERSBACH, H.; HÓLM, E. V.; ISAKSEN, L.; KÅLLBERG, P.; KÖHLER, M.; MATRICARDI, M.; MCNALLY, A. P.; MONGE-SANZ, B. M.; MORCRETTE J. - J.; PARK, B. -K.; PEUBEY, C.; DE ROSNAY, P.; TAVOLATO, C.; THÉPAUT, J. -N; VITART, F. The ERA-Interim reanalysis: configuration and performance of the data assimilation system. Quarterly Journal of the Royal Meteorological Society, v. 137, p. 553-597, 2011.

GAN, M.A.; RAO, V.B. The influence of the Andes Cordillera on Transient Disturbances. Monthly Weather Review, v.122, p.1141-1157, 1994.

GARREAUD, R.D.; WALLACE, J.M. Summertime incursions of mid-latitude air into tropical and subtropical South America. Monthly Weather Review, v.126, p.2713-2733, 1998.

FISCH, G.; MARENGO, J. A.; NOBRE, C. A. Uma Revisão Geral sobre o Clima da Amazônia. Acta Amazônica, v. 28, n.2, p. 101-126, 1998.

IBGE. Meso e microrregião geográfica 1990. Rio de Janeiro, 2000. 1 atlas. Escala 1:15000000.

KOUSKY, V.E. Frontal Influences on Northeast Brazil. Monthly Weather Review, n.107, p. 1140-1153, 1979. 
LEMOS, C.F; CALBETE, N.O. Sistemas Frontais que Atuaram no Brasil de 1987 a 1995. Net, 1996. Climanálise especial, edição comemorativa de 10 anos. MCT/INPE-CPTEC.

http://climanalise.cptec.inpe.br/ rclimanl/boletim/cliesp10a/14.html. Acesso em 01 set. 2011.

MORAIS, M.A.; CASTRO, W.A.C.; TUNDISI, J.G. Climatologia de Frentes Frias sobre a Região Metropolitana de São Paulo (RMSP), e sua Influência na Limnologia dos Reservatórios de Abastecimento de Água. Revista Brasileira de Meteorologia, v.25, p.205-217, 2010.

REBOITA, M. S.; AMBRIZZI, T.; DA ROCHA, R. P. Relationship between the Southern Annular Mode and Southern Hemisphere Atmospheric Systems. Revista Brasileira de Meteorologia, v.24, p.48-55, 2009.

REBOITA, M.S.; DA ROCHA, R.P.; AMBRIZZI, T.; SUGAHARA, S. South Atlantic Ocean Cyclogenesis Climatology Simulated by Regional Climate Model (RegCM3). Climate Dynamics, v.35, p.1331-1347, 2010a.

REBOITA, M.S.; GAN, M.A.; ROCHA, R.P.; AMBRIZZI, T. Regimes de Precipitação na América do Sul: Uma Revisão Bibliográfica. Revista Brasileira de Meteorologia, v.25, p.193-212, 2010b.

RODRIGUES, M.L.G.; FRANCO, D.; SUGAHARA, S. Climatologia de Frentes Frias no Litoral de Santa Catarina. Revista Brasileira de Geofísica, v.22, p.135$151,2004$.

SATYAMURTY, P., MATTOS, L.F. Climatological Lower Tropospheric Frontogenesis in the Midlatitudes due to Horizontal Deformation and Divergence. Monthly Weather Review, v.117, p. 1355-1364, 1989.

SIMMONDS, I.; KEAY, K.; BYE, J.A.T. Identification and Climatology of Southern Hemisphere Mobile Fronts in a Modern Reanalysis. Jounal of Climate, v.25, p.1945-1962, 2012.

WMO. Guide to Climatological Practices. v.100, 3.ed, 2011. 